\title{
Mobile Location-Based Augmented Reality Applications for Urban Tourism Storytelling
}

\author{
Rui Nóbrega, João Jacob, António Coelho \\ FEUP, Faculdade de Engenharia da \\ Universidade do Porto and \\ INESC TEC, Instituto de Engenharia de \\ Sistemas e Computadores, Tecnologia e Ciência \\ Porto, Portugal \\ Email: http://fe.up.pt/gig, \\ \{ruinobrega, joao.jacob, acoelho\}@fe.up.pt
}

\author{
Jessika Weber \\ João Ribeiro, Soraia Ferreira \\ NHTV, University of Applied Sciences FEUP, Faculdade de Engenharia da \\ Breda, Netherlands \\ Email: weber.j@nhtv.nl
}

\begin{abstract}
Creating a mobile urban tourism storytelling application presents several interactivity challenges on how to convey an engaging multimedia experience on-site. This article describes a methodology for fast prototyping of a multimedia mobile applications dedicated to urban tourism storytelling. The application can be a game that takes advantage of several locationbased technologies, freely available geo-referenced media, and augmented reality for immersive gameplay. The goal is to create serious games for tourism that follow a main narrative but where the story can automatically adapt itself to the current location of the player, assimilate possible detours and allow posterior out-of-location playback. Adaptable stories can use dynamic information from map sources such as points of interest (POI), elevation or virtual buildings. The main focus is for these locationbased storytelling games to create more engagement between the tourists and the urban environment. To explore this concept, an application was designed for the city of Porto: Unlocking Porto. This location-based game with a central, yet adaptable, story engages the player into the main sights following an augmented reality path while playing small games. The article discusses and presents solutions for media acquisition, interactive storytelling, game-design interface and multi-disciplinary coordination for mobile app development.

Keywords-augmented reality; location-based games; mobile applications; tourism applitions
\end{abstract}

\section{INTRODUCTION}

The implementation of context-aware mobile AR applications into tourism provides many benefits for the tourist experience. These apps can be used to enhance visitor learning in cultural heritage sites [1] or advance the interaction between the visitor and tourist artifacts [2] and often assume the form of games. Games have the power to create more engagement with the tourist destination through storytelling [3], [4], playfulness and mobile learning.

The demand for the fast creation of such games is increasing, with a large demand for changing new content to be delivered at a high pace. This requires new approaches for multimedia content creation beyond traditional field research. This includes using geo-location utilities and frameworks [5], [6] to gather points of interest (POI) or mining social networks

978-1-5386-2080-9/17/\$31.00 (C)2017 IEEE
[7] in order to get collaborative feedback from other tourists or visitors.

The use of mobile applications for mobile devices is rapidly growing and has become apparent for the worlds largest industry travel and tourism. With more than $\$ 6$ trillion direct and indirect economic impact of the industry, tourism has a huge market to facilitate new innovation. Tourists use mobile devices before [8], during and after their holidays to retrieve geographic information [9], to mediate tourist sites [10] or to share experiences in social networks. Falling roaming charges will facilitate further increasing usage of these applications abroad. The nature of tourism is to create extraordinary experiences [11], thus there is a constant search for innovative tools and new technologies to enhance the tourist experience.

Smartphones, with the latest GPS-technology and built-in camera, enable players to use the real world as the playground and take gameplay outside into the real world. While the quantity and quality of mobile devices are increasing, mobile gaming attracts a wide range of user groups playing in different contexts [12]. Recent advancements provide more people than ever access to hardware and new mobile game experiences [13].

Mobile gaming is lately evolving in travel and tourism opening new forms of creating enhanced experiences for tourists. Location-based [5], Augmented Reality (AR)[14], Pervasive or Serious Games [15] open the possibility to create deep, personalized and interactive experiences tourists are striving for by actively engaging the tourist with places and people throughout gameplay. This creates a deeper understanding and distinct experiences for the tourist with his immediate environment applying playful and gameful concepts.

In order to gain an understanding of tourists requirements for such games, the following research question was taken into consideration: how to tell a story in the city with a multimedia system, making the user discover important locations in the city, understand its history and provide an autonomous and, at the same time, social interaction in order to create engaging tourist experiences. An important requirement is to create a fast prototype using a multidisciplinary team in a 


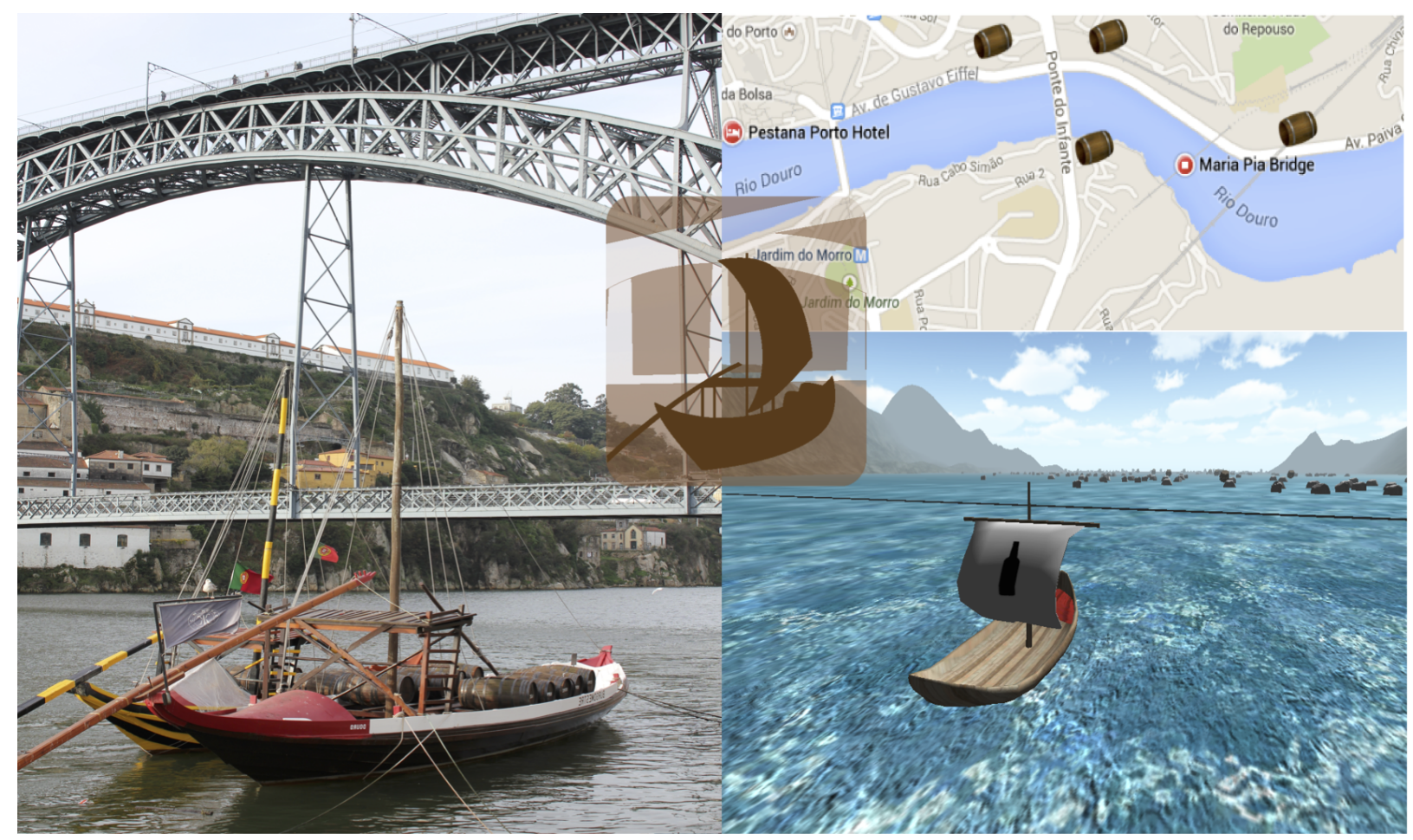

Fig. 1: Location-based storytelling game for tourism in the city of Porto.

short ammount of time.

The game prototype is based on a mobile multimedia system, which features a storytelling game that uses the real city as a game board [16]. Technologically this requires the use of mobile devices, using location-based games to move the user from place to place [5], augmented reality (AR) to immerse the player in the urban environment with in loco information [17], [18] and multimedia capabilities to display a story through videos, images, texts and games [16]. The media sources for these stories and games should contain static and dynamic elements [7]. The main story media sources consist of an extensive background research of the desired tourism destination. The multimedia location and AR based games will take advantage of external dynamic sources such as freely available geo-referenced information like maps, social travel websites or online collaborative tourism recommendation systems.

In this article we are presenting the result of a fast prototyping approach, which lead to the creation of a full multimedia experience in less than one month using a multi-disciplinary team. The design concept of an urban adventure game for tourists takes advantage of internal and external media sources to improve the storytelling strategy. As a proof-of-concept, a location-based game designed for tourism in the city of Porto, Portugal is presented. The game, called Unlocking Porto, takes advantage of location-based technologies, augmented reality and mobile 3D graphics [19] as depicted in Figure 1. In the end several consideration are drawn covering the lessons learnt and future directions.

\section{Mobile AR AND LOCATION-BASED STORYTELLING IN GAMES}

Current multimedia systems in tourism enhance the reality with a digital layer of factual information about people, places and tourist relevant locations that would otherwise be invisible. The many Augmented Reality (AR) apps for travel and tourism such as Junaio ${ }^{1}$ and Wikitude ${ }^{2}$ curate much useful information to supply travellers with facts about the place visited. In many respects, these systems only loosely present information of tourist POIs as opposed to telling a whole story about places and engage the user into a narrative of the destination. Every place tells a story which can be told via new mobile technologies corresponding to the users current location via GPS and thus turning urban environments into a stage on which the narrative unfolds [3]. Location-based storytelling is a powerful tool for tourism destinations to draw people in and make them understand the places they visit in a more interactive way than just presenting bare facts [20].

As with the further development of smartphones, creating engaging experiences with location-based mobile AR Games evolves from a niche to a wider audience. Mobile game design is currently experiencing a flourishing interest from game designers and game researchers [1], [13]. However, knowledge about game design for location-based mobile AR games in tourism are at an early stage as current research shows [5].

Mobile game for tourists started with REXplorer, a pervasive game for the city of Regensburg, Germany with the aim to

\footnotetext{
${ }^{1}$ Junaio, http://www.junaio.com

${ }^{2}$ Wikitude, http://www.wikitude.com
} 
adduce the history of the city and give direction to the walking path through the city supported by audio-recorded material and in-game chat [21]. Another example of mobile game-based learning has been conducted with Frequency 1550, a mobile city game placed in the medieval town of Amsterdam focusing on historical location-based storytelling [8]. The locationbased mobile AR Game TimeWarp is concerned about how form and content issues impact the players experience of presence. The game is anchored in the city of Cologne, Germany, drawing on famous characters and historical places of the city and exploring the boundaries between gaming and physical space. The study focuses on exploring the relationship between game design, the city context, narrative, embodiment and interaction. Outcomes revealed that game design needs to be strongly anchored either in a narrative or a location perspective in order to be successful [13].

Despite previous research on mobile location-based and AR games, little is known about how to design these games in a tourism context. This project explores the novel interdisciplinary topics of multimedia storytelling and game design in tourism to aim for creating engaging experiences for tourists. The use of location-based mobile AR games can intensify the way tourists interact with the physical and social environment and the way individual experiences are made.

These location-based AR games still face the challenge of creating engaging experiences of the player with the environment although game designers scoop from a rich toolbox of game mechanics. Current games embrace elements of contextawareness such as using urban landmarks for the gameplay to familiarize players with places or create interaction with the physical environment through interactive puzzles and quizzes. Another form of player engagement emerges in the social interaction among players and non-players liberated through role playing and engaging narratives.

\section{Game Methodology And Concepts}

The creation of a game designed to enhance the exploration experience of a tourist has several challenges and requirements in many areas. In our methodology for fast prototyping of a multimedia experience the first step was the creation of a multi-disciplinary team in the following areas:

- Economy: Evaluate the tourist needs, what is he looking for? Who is the tourist? What can the business plan be?

- Storytelling: What stories can potentiate the value and interest of the application? Background research on the tourism destination, creation a line of thought to drive the story.

- UX design / Game designer: What will the experience, the interface and the game mechanics be? Interface and User Experience design.

- Art design: Collection and creation of media elements to display in the application.

- Sound Design: Engage the player through sound.

- Game Development: Implementation of the game's design.
- System and Mobile Technologies: Gathering external information sources, creating a server and enabling a multimedia framework. Enabling location-based technologies. Logic and game mechanics implementation.

To validate the developed location-based game and the AR multimedia framework, a case study was created with a large team from the aforementioned areas.

\section{A. Case Study: Unlocking Porto}

Unlocking Porto is a location-based (LB) augmented reality (AR) game for tourists set in Porto, Portugal, where the player takes on the role of a Rabelo (traditional Douro river boat) boat sailor who has to reach the Port wine cellars with the maximum number of barrels.

The aim of the game is to create an engaging game experience for tourists by interacting with and learning about the tourist location. The game combines educational and playful experiences for visitors of the city providing information about the history of Port wine and its journey from the Douro region to the many wine cellars in the city.

The implementation of the game involved a coordinated effort that created the game concept presented in Figure 2. The main concept was to create a mobile game for tourists, which allowed them to explore the city. The player can be in three main modes Couch Mode, LB \& AR Game and InGame-Minigame. Initially the game starts in couch mode, by which the player can be anywhere in the city (namely on the hotel couch). At this point he learns statically about the city stories and plays a quiz game. In the LB \& AR Game mode, the players physical position is used to direct him to POIs where the story is unveiled to him while he learns about the city. When the player reaches certain points in the history InGames are unlocked as a reward.

What is important to recall is that the player can start the game anywhere in the city. So, it requires an offline mode where the GPS position is not needed (Couch mode), an interactive experience to navigate the city. This interactive experience should complement the live (GPS-enabled) experience and not be a substitute. The player is free to follow directions from the location-based system but can always ignore the direction or the screen of the app thus enjoying the real view. In special locations, the user is notified to enter the AR mode or to play a Mini-game. These are rewards and notifications of POIs.

\section{EnTERTAinment SOLUTION}

The main multimedia system solution for the mobile location-based AR framework is described in Figure 3.

The main goal of the multimedia system is to enable the creation of stories through the use of traditional media such as text, images and videos but also interactive media such as location-based and map-based technologies, augmented reality in-loco visualizations, quiz games and virtual 3D games.

The first source of information for the system is the internal sensors from the mobile phone [21], [5]. These include all the required sensors to get the location of the device and its 


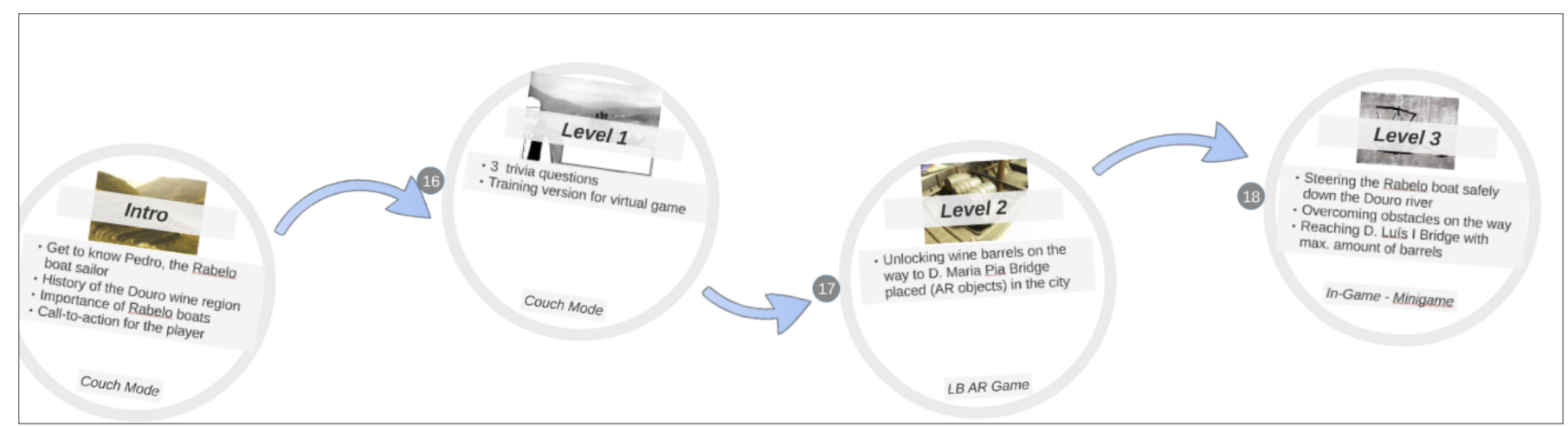

Fig. 2: Game concept and game flow.

orientation in the physical world. In the future these sensors may include depth sensing cameras (such as in Google Project Tango) or barometers to better measure elevation. The camera of the smartphone is used for the AR setting [22].

External media sources of information are required to enrich the stories with geographical information: Bing Maps API can be used for obtaining real-world satellite imagery, whereas elevation of AR objects and player can be correctly calculated using Google's Elevation API, and information about POIs, can be gathered from the collaborative map system, OpenStreetMaps. In the future these media external APIs can be complemented by social geo-located media such as Foursquare, which allows access to a large number of POIs that are designated and reviewed collaboratively by its users.

Being a storytelling application it is always important to have a main conduction story or set of stories. This requires an extensive field research to collect information, texts, images and other media of an urban environment.

The system is currently implemented using the multi-platform game development framework Unity3D (http://unity3d.com) operating in several different Android 4.+ smartphones with a wide range of diversity in terms of hardware specifications.

\section{A. Storytelling and Game Mechanics}

The use of a narrative or creating a main character increases the audience connection and engagement with the place or event that you want to promote [16]. Storytelling can thus be a perfect method to convey the city experience to the tourist. In this article we are mainly concerned about mobile storytelling, but tourists search information through several types of media (web, tv, mobile apps) thus, many times the creation of a multimedia presence really requires a transmedia storytelling approach [16].

The game presents several stories from the city, but invites the player to follow one major plot. Following the design concept presented in Figure 4, the first scene introduces Pedro, the Rabelo boat sailor (traditional Douro river boat seen in Figure 1) and the Douro river region with its importance for the Port wine. The player has been given a call to action to

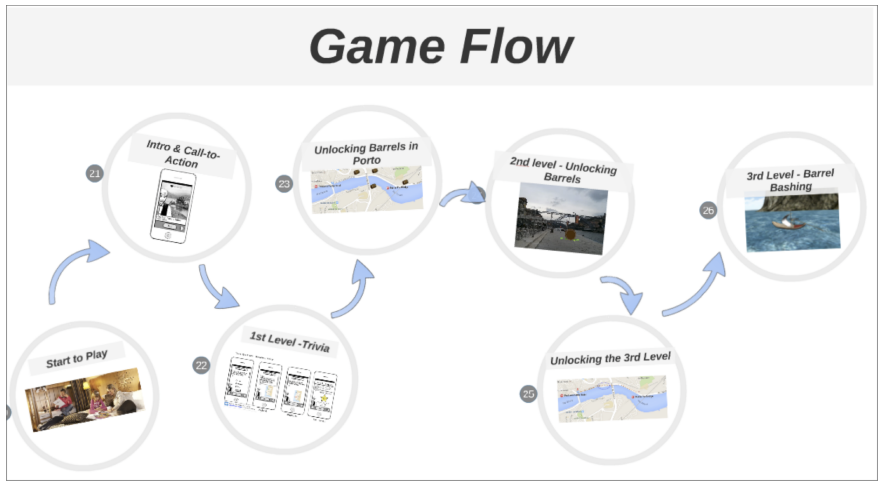

Fig. 4: Game flow concept.

help Pedro navigate the Rabelo boat with the barrels of Port wine to the wine cellars in Porto.

Shown in Figure 4, the game starts with the introduction of the narrative and the call-to-action for the player to help the NPC (Non-Playable Character) with his tasks to sail the Port wine barrels safely from the Douro region to the wine cellars in Porto. In order to become a Rabelo boat sailor, the player is asked to solve trivia questions (Figure 5a) and play a first training session in which he learns to navigate the boat.

After having successfully accomplished the first level, the second level will be unlocked and the player is asked to collect virtual barrels that are placed in the town of Porto and unlocked by pointing the mobile phone towards them to tap and collect in AR mode. These virtual barrels guide the way to the first location-based play location.

The second level (Figure 6b) requires the player to physically explore the city of Porto in order to search for virtual Port wine barrels being spread all over the city of Porto and leading the way to D. Maria Pia Bridge like bread-crumps. Having arrived there, the player enters the third level and loads a boat and virtually sails down the Douro River. The Rabelo boat is presented in a mini-game, the third level, on the river simulating the navigation of those boats down the stream. This third level (Figure 7) projects the player into a virtual reality gameplay in which he steers the Rabelo boat through a Douro River simulation comprising of different obstacles such 


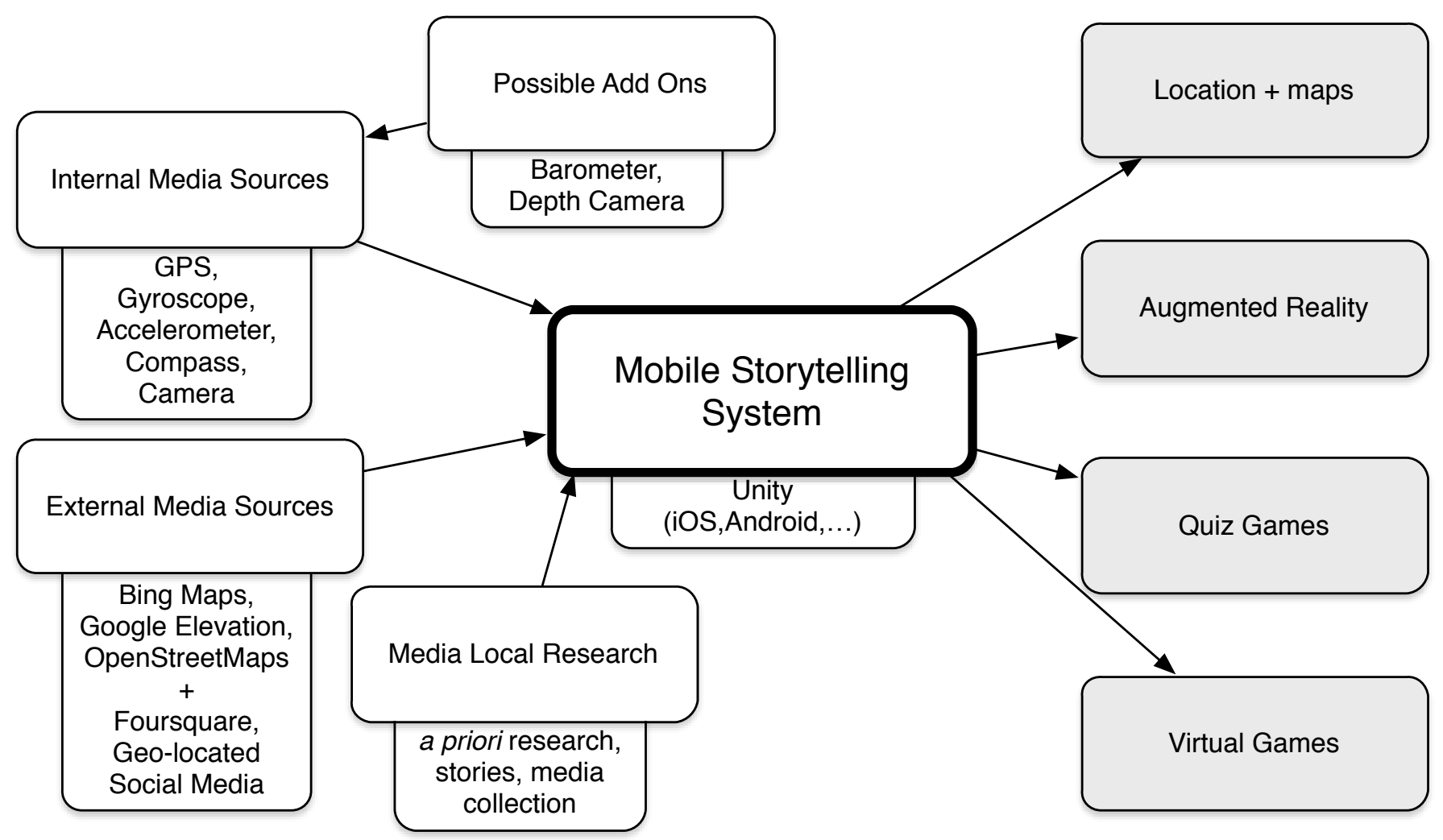

Fig. 3: System diagram with the media sources and, on the right, the type of user interfaces, which were developed for the mobile storytelling system.

as rocks, seagulls and fishers on the way. The aim is to arrive at the D. Lus I Bridge with as many barrels on the boat as possible. This level can be repeated several times.

Finally, the end of the story is the final delivery place where the barrels are rolled down in form of Augmented Reality objects leading to the location of the wine cellars in Gaia (opposite side of Douro River from Porto). In Gaia, gained barrels from the gameplay can be redeemed for souvenirs in the shops or used as a discount for the wine cellar exhibition entry.

\section{B. Visual Interface}

The game interface is divided into (1) game introduction with quiz (Figure 5), (2) location-based map with Augmented Reality gameplay (Figure 6) and (3) a virtual world gameplay (Figure 7). These experiences unfold in the different levels of the game. Depending on the played level, the different experiences are revealed in different forms and with different content. The visual aesthetics include images in black and white, with a sepia filter in the menus and story texts to give a feeling of being set back into the 19th century. Figures 5, 6 and 7 present the main game modes at concept level and implementation stage.

The player enters the game in a couch mode independently from a particular location in order to familiarize with the game story and the mechanics. The game starts with the game logo, which fades into the game menu. From the menu the player can navigate to the different levels, game options, game map and high scores. Every action, answering correctly to a quiz or collecting barrels increases the players score (in the current game, the number of barrels). The final score can be used in the end for marketing purposes such as real voucher redeems.

In the beginning of the story and at certain important locations, the player learns about the city and is sometimes presented with simple trivia questions. These questionnaires presented in Figure 5 are meant to challenge the tourist to learn about the story and the tourist destination.

Figure 6 presents the barrel navigation system that guides the user to the places where the story takes place or to the nearest story point if the user is outside the geographical scope of the narrative. Figure 7 presents the Barrel Bashing game where the player is asked to navigate the boat through the river by tapping on the left or right half of the screen. The goal of this game is to have a relaxing fun moment where the tourist has to retrieve as much barrels as possible without hitting a rock. This game is used to motivate the tourist when he is in a less interesting place on the path for a major landmark. After unlocking the game once, it can be replayed again from the main menu. 

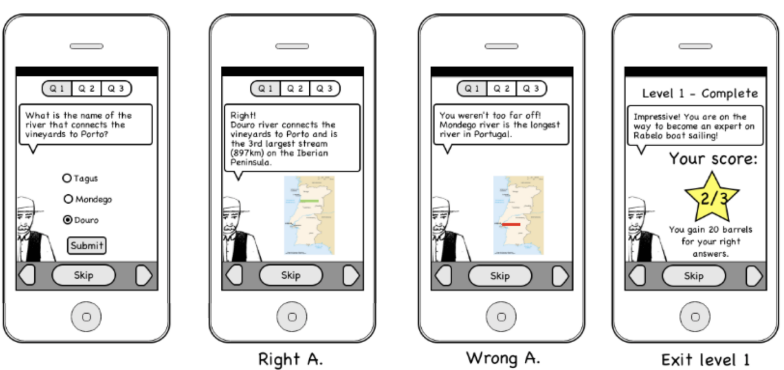

(a) Storyboard of the quiz designed to test the knowledge of the player and to inform him of the correct answer.

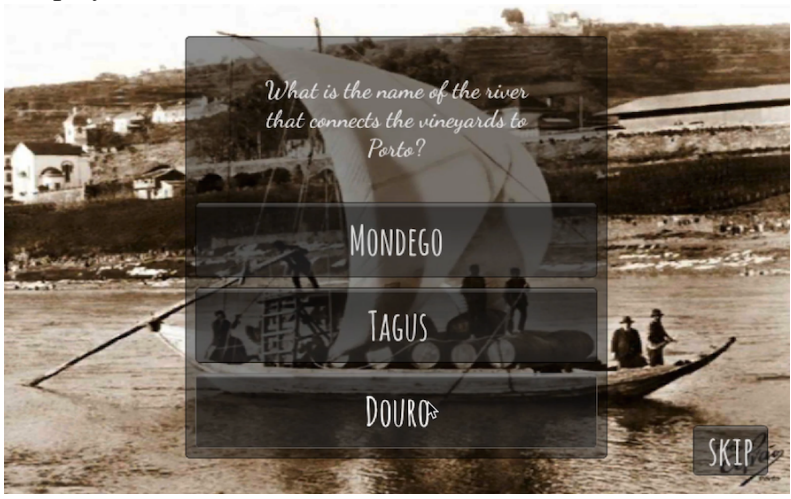

(b) Current implementation with the final design.

Fig. 5: Interface snippets.

\section{LESSONS LEARNED AND INSIGHTS}

From the experience of building this application several conclusions and lessons can be retrieved for the future. Technically, location-based games are very dependent on the accuracy of the GPS signal and its reception by the device. The error can create strange, displaced and frustrating experiences. The applications should be able to cope with a lack of signal and allow a manual introduction of current location. Using AR has its own problems, with many smartphones having poor cameras or poorly illuminated screens in outdoor scenarios.

The automatic information gathering system does not completely replace a traditional storytelling system where contents are gathered through field research and organized by content producers (writers, artists, storytellers). It is rather a complement, which helps to spur the interactivity by allowing additional content when the user is interested in deliberately not following the main story path or when the tourist only consults the application occasionally or in Couch Mode.

Games are an interesting approach for tourists, especially if they possess a reward system in which the user is awarded a prize for reaching a certain location or answering questions correctly about the story or destination. Tourists were presented with mini-games as rewards in the application. While mini-games are unlocked when the tourist enters a certain location in the city, it is important to enable playability of the unlocked mini-games afterwards when the player is outside the given location, or in other words, in couch mode at the

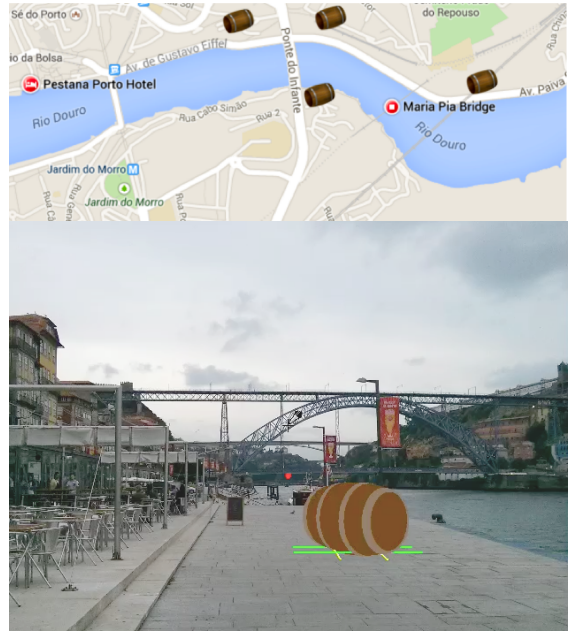

(a) Concept map path and desktop augmented barrel using the Magnetic Augmented Reality Objects technique [22].

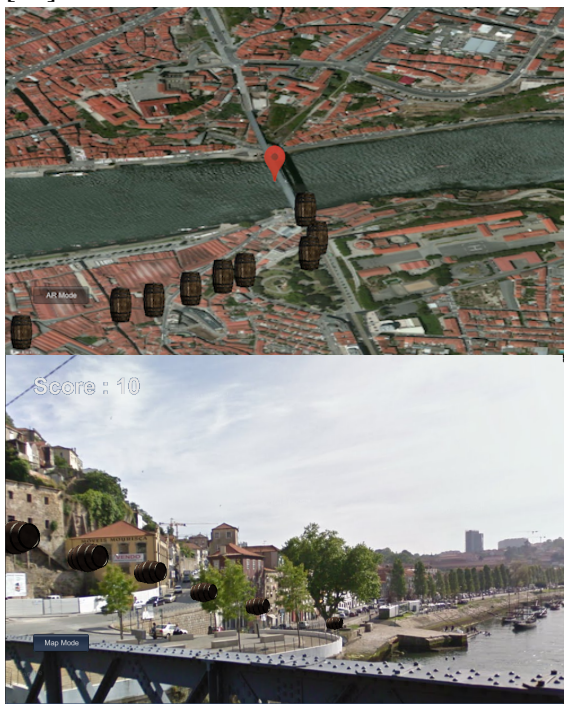

(b) Implemented mobile application screenshots with a path of barrels along the river.

Fig. 6: Map navigation. The player is encouraged to follow a path of virtual barrels. Whenever the player approaches an area with a barrel the camera is turned on and s/he can collect a barrel and increase the score.

hotel. In the end barrels or the score can be converted into a physical prize.

Finally this type of game can be used to improve the tourist experience but can also be used to lead tourists to certain locations by displaying brand advertisement and promotion.

\section{Conclusions}

The creation of game-based storytelling applications requires a well thought game design in order to identify the specific requirements of the tourists who behave like a player in the unfamiliar destination. Tourist destination management organizations (DMOs) need to know for which target audience 


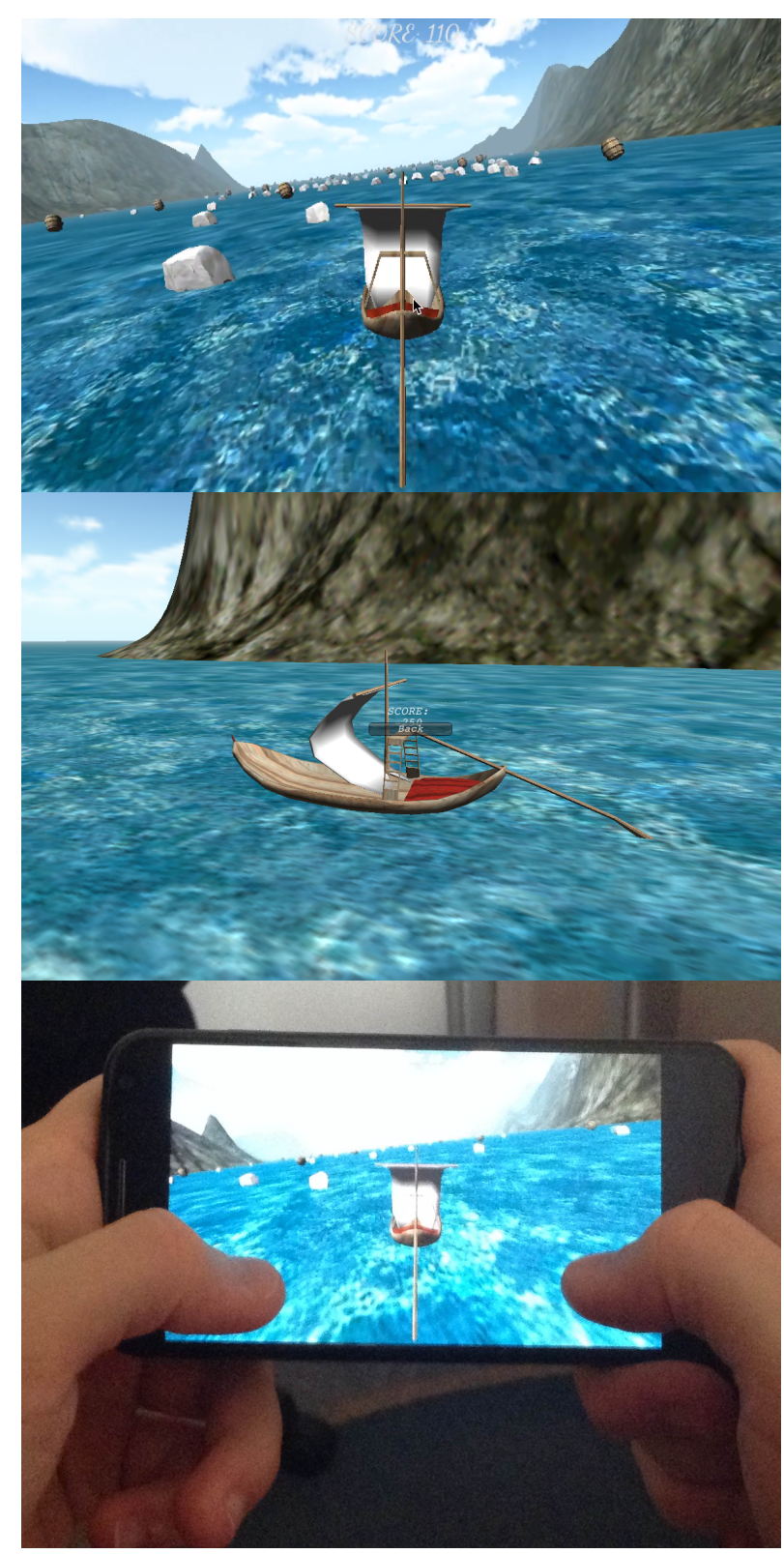

Fig. 7: Mini-game where the player has to collect as many barrels as possible in the river Douro. The mini-games are unlocked at certain important locations in the city as a reward.

these interactive systems are designed and which goal they want to achieve the implementation of location-based storytelling games. As the development of those systems involves knowledge of technological possibilities, game design and development as well as of the tourist destination, it requires the collaboration of a multidisciplinary team.

Being a location-based storytelling system, game designers face the challenge of ever changing content and more and more interactivity requirements. Using location-based services, other APIs and location-enabled content from social media sources can improve the automatic interactivity level and life span of traditional storytelling applications. Fast multimedia design prototyping has the advantage of producing large quantities of consumable information in a short period of time to retrieve user feedback in order to iteratively improve game design. It can have, however, not enough critical and curated information and detail brought by traditional story gathering techniques.

The current application features a full-fledged locationbased game, using maps, an augmented reality utility and 3D game complement. The game was created for mobile platforms and follows a main story around the city of Porto and its wine production tradition. The game-base storytelling system has a well-designed strategy and all technologies were tested and implemented. The next stage will be the improvement of the user interface with additional user studies in order to deploy a final version, which will be used to create more engaging tourist experiences with the city of Porto.

\section{ACKNOWLEDGEMENTS}

The research leading to these results has received funding from the European Union's Horizon 2020 - The EU Framework Programme for Research and Innovation 20142020, under grant agreement No. 687676. Additionnaly it is part of Foureyes. FourEyes is a Research Line within project TEC4Growth Pervasive Intelligence, Enhancers and Proofs of Concept with Industrial Impact/NORTE-01- 0145-FEDER000020 financed by the North Portugal Regional Operational Programme (NORTE 2020), under the PORTUGAL 2020 Partnership Agreement, and through the European Regional Development Fund (ERDF).

\section{REFERENCES}

\section{REFERENCES}

[1] V. Lombardo, R. Damiano, Storytelling on mobile devices for cultural heritage, New Review of Hypermedia and Multimedia 18 (2012) 11-35. doi:10.1080/13614568.2012.617846.

[2] H. Kim, J. Schliesser, Adaptation of Storytelling to Mobile Information Service for a Site-Specific Cultural and Historical Tour, Information Technology \& Tourism 9 (2007) 195-210. doi: $10.3727 / 109830507782166971$.

[3] J. Paay, J. Kjeldskov, A. Christensen, A. Ibsen, D. Jensen, G. Nielsen, R. Vutborg, Location-based storytelling in the urban environment, Proceedings of the 20th Australasian Conference on Computer-Human Interaction Designing for Habitus and Habitat - OZCHI '08 (2008) 122doi:10.1145/1517744.1517786. URL http://dl.acm.org/citation.cfm?id=1517744.1517786

[4] J. Stenros, J. Holopainen, A. Waern, M. Montola, E. Ollila, Narrative friction in Alternate Reality Games: Design insights from conspiracy for good, in: Proceedings of DiGRA 2011 Conference: Think Design Play, 2011.

[5] J. Jacob, A. Coelho, Issues in the Development of Location-Based Games, International Journal of Computer Games Technology 2011 (2011) 1-7. doi:10.1155/2011/495437.

URL http://www.hindawi.com/journals/ijcgt/2011/495437/

[6] S. Matyas, C. Matyas, C. Schlieder, P. Kiefer, H. Mitarai, M. Kamata, Designing location-based mobile games with a purpose: collecting geospatial data with CityExplorer, Proceedings of the 2008 International Conference on Advances in Computer Entertainment Technology (2008) 244-247doi:10.1145/1501750.1501806 URL http://dl.acm.org/citation.cfm?id=1501806

[7] S. Papadopoulos, Y. Kompatsiaris, A. Vakali, P. Spyridonos, Community detection in Social Media, Data Mining and Knowledge Discovery 24 (3) (2011) 515-554. doi:10.1007/s10618-011-0224-z. URL http://link.springer.com/10.1007/s10618-011-0224-z 
[8] U. Gretzel, D. R. Fesenmaier, Y. J. Lee, I. Tussyadiah, Narrating Tourist Experiences: The Role of New Media, in: Tourist Experiences: Contemporary Perspectives., Routledge, 2011, pp. 171-182.

[9] I. P. Tussyadiah, F. J. Zach, The role of geo-based technology in place experiences, Annals of Tourism Research 39 (2012) 780-800. doi:10.1016/j.annals.2011.10.003.

[10] H. Kennedy-Eden, U. Gretzel, A taxonomy of mobile applications in tourism, e-Review of Tourism Research 10 (2012) 47-50.

[11] B. J. Pine, J. H. Gilmore, The experience economy: work is theatre \& every business a stage, Vol. 40, 1999. doi:10.1080/02642069700000028.

[12] T. Carrigy, K. Naliuka, N. Paterson, M. Haahr, Design and evaluation of player experience of a location-based mobile game, in: Proceedings of the 6th Nordic Conference on Human-Computer Interaction: Extending Boundaries, NordiCHI '10, ACM, New York, NY, USA, 2010, pp. 92 101. doi: $10.1145 / 1868914.1868929$.

URL http://doi.acm.org/10.1145/1868914.1868929

[13] R. Wetzel, L. Blum, W. Broll, L. Oppermann, Designing Mobile Augmented Reality Games, Handbook of Augmented Reality (2011) 513-539doi:10.1007/978-1-4614-0064-6. URL http://link.springer.com/10.1007/978-1-4614-0064-6

[14] R. Nóbrega, D. Cabral, G. Jacucci, A. Coelho, Nari: Natural augmented reality interface, in: Proceedings of the 10th International Conference on Computer Graphics Theory and Applications, GRAPP 2015, SCITEPRESS - Science and Technology Publications, Lda, Portugal, 2015, pp. 504-510. doi:10.5220/0005360305040510.

URL https://doi.org/10.5220/0005360305040510

[15] T. Marsh, Serious games continuum: Between games for purpose and experiential environments for purpose, Entertainment Computing 2 (2) (2011) 61-68, cited By 26. doi:10.1016/j.entcom.2010.12.004.

URL http://www.scopus.com/inward/record.url? eid=2-s2.0-79959948166\&partnerID=40\&md5= bc8bd6410c421ae6cd3931588fc4c9e0

[16] S. Ferreira, A. P. Alves, C. Quico, Location Based Transmedia Storytelling in Social Media Peter s TravelPlot Porto Case Study, E Review of Tourism Research (eRTR) ENTER 2014 Conference on Information and Communication Technologies in Tourism 5.

[17] Y. Takeuchi, K. Perlin, ClayVision: The (elastic) image of the city, in: Proceedings of the 2012 ACM annual conference on Human Factors in Computing Systems (CHI '12), ACM, Austin, TX, USA, 2012, pp. 2411-2420.

URL http://www.tinylab.me/mobile/publications/chi12cv.pdf

[18] D. Wagner, G. Reitmayr, A. Mulloni, T. Drummond, D. Schmalstieg, Real-time detection and tracking for augmented reality on mobile phones, IEEE Transactions on Visualization and Computer Graphics 16 (3) (2010) 355-368.

URL http://www.ncbi.nlm.nih.gov/pubmed/20224132

[19] R. Nóbrega, N. Correia, Interactive 3d content insertion in images for multimedia applications, Multimedia Tools Appl. 76 (1) (2017) 163 197. doi: $10.1007 / \mathrm{s} 11042-015-3031-5$. URL https://doi.org/10.1007/s11042-015-3031-5

[20] S. Göbel, F. Mehm, S. Radke, R. Steinmetz, 80Days: Adaptive digital storytelling for digital educational games, CEUR Workshop Proceedings 498.

[21] S. Benford, M. Flintham, C. Greenhalgh, M. Adams, Coping with uncertainty in a location-based game, Pervasive Computing, IEEE 2 (3) (2003) 34-41. doi:10.1109/MPRV.2003.1228525.

[22] R. Nóbrega, N. Correia, Magnetic augmented reality: virtual objects in your space, in: Proceedings of the 2012 International Working Conference on Advanced Visual Interfaces (AVI'12), ACM, Capri Island, Naples, Italy, 2012, pp. 332-335.

URL http://dl.acm.org/citation.cfm?id=2254620 